\title{
Slow recovery of ovarian endocrine function after adnexal detorsion in a case of delayed diagnosis
}

\author{
Jelena Kisic-Trope $\cdot$ Erik Qvigstad
}

Received: 18 July 2011 /Accepted: 22 August 2011 /Published online: 3 September 2011

(C) Springer-Verlag 2011

\section{Introduction}

Adnexal torsion is defined as total or partial rotation of the adnexa around its vascular axis, resulting in ischemia. Without treatment, the ischemia will result in necrosis of the ovary, fallopian tube, or the whole adnexal structure. Traditionally, adnexal torsion has been treated by salpingo-oophorectomy, but since most of the patients are of reproductive age, preservation of the ovary is desirable [1].

The expected benefits of adnexal conservation are restoration of the endocrine and germinal ovarian function [2]. The adnexa can retrieve its functional integrity after surgery [1,3], and follicle growth has been observed by ultrasonography within 4 months [4]. We report a case of successful conservative treatment of adnexal torsion diagnosed and treated after 10 days of delay, in a woman who previously had removed the other adnexa due to torsion. Recovery of the menstrual periods, endocrine function, and follicle growth were seen within $3-5$ months after surgery.

J. Kisic-Trope · E. Qvigstad

Department of Gynecology,

Oslo University Hospital and University of Oslo,

Oslo, Norway

J. Kisic-Trope $(\bowtie)$

Department of Gynecology, Oslo University Hospital Ullevål, 0407 Oslo, Norway

e-mail: go-trope@online.no

\section{Case presentation}

The patient was a 30-year-old woman, nulligravida, who had had the appendix removed in a younger age, and 6 years previously, she was treated for adnexal torsion in another hospital with removal of the left adnex. She presented with a 2-day history of lower abdominal pain, predominantly on the right side, with sudden onset. At vaginal ultrasound examination, a simple cyst of $2 \mathrm{~cm}$, with normal color Doppler, was seen in the right ovary, and was interpreted as ruptured corpus luteum with bleeding. The patient was dismissed with painkillers. Since the pain persisted, she was referred back to the gynecological unit 7 days later. On admittance, gynecological examination and vaginal ultrasound revealed a tender $10 \times 7.5-\mathrm{cm}$ mass to the right side of the pelvis. No obvious cyst was possible to detect. Adnexal torsion with the enlargement of the ovary due to prolonged venous stasis and edema was suspected. C-reactive protein was $120 \mathrm{mg} / \mathrm{l}$, which corresponded well with the delayed diagnosis of an ovarian torsion.

A laparoscopy, performed the same day, revealed the right adnexa to be twisted twofold, edematous, ischemic, and dark blue in appearance. Initial adhesion formation and peritoneal reaction with fibrin deposits were visible in tissue adjacent to the enlarged ovary (Fig. 1). After detorsion, the fallopian tube quickly regained normal color, but the color of the large ovary hardly improved during the surgery time. In an attempt to reduce the risk of further torsion events, ovariopexy was performed. We used $2-0$ slowly absorbable suture and fixed the proximal part of the ovary to the pelvic 


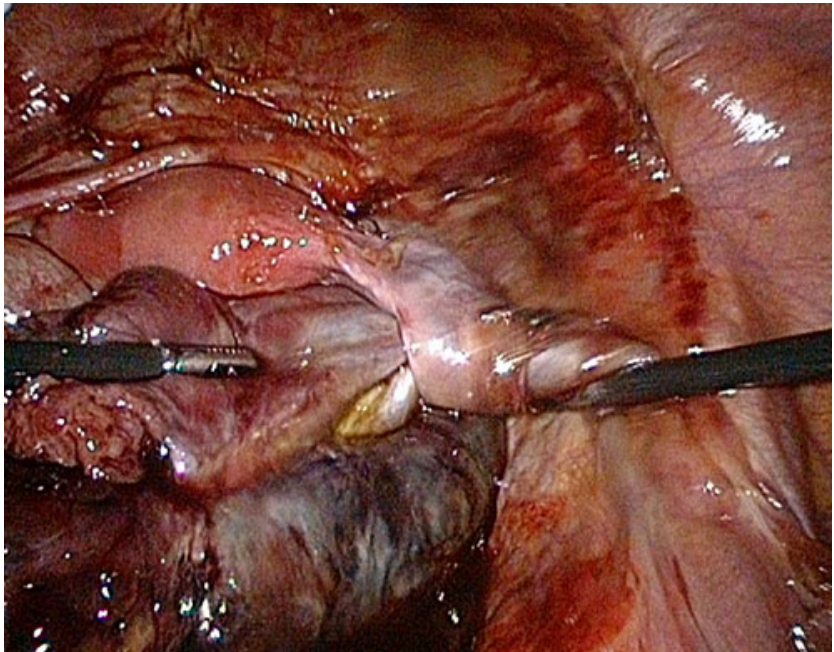

Fig. 1 Visible peritoneal reaction on the pelvic wall and bladder peritoneum after the ovary was partially detwisted

sidewall with intracorporeal technique. The postoperative period was uneventful, and she went home after 3 days.

The size of the ovary was normalized in about 4 weeks following surgery as shown by vaginal ultrasound examination. Power Doppler ultrasound showed flow inside the whole ovary on examination 10 days postoperatively. The menstrual periods returned after about 3 months, with regular bleedings from the next month. The patient experienced hot flushes during the first 2-3 months, and her hormonal levels were in accordance with menopause. Table 1 shows considerable elevated follicle-stimulating hormone and luteinizing hormone in the first months following surgery, normalized estradiol after 2 months with still elevated gonadotropins and complete normal endocrine profile 5 months after the laparoscopy with the antimüllerian hormone $(\mathrm{AMH})$ also well within normal values.

\section{Discussion}

Laparoscopy should be the preferred surgical approach in patients with ovarian torsion, and in women of reproductive

Table 1 Hormonal levels after surgery

\begin{tabular}{lllll}
\hline Time postoperatively & $\begin{array}{l}\text { FSH } \\
(\mathrm{IE} / \mathrm{l})\end{array}$ & $\begin{array}{l}\mathrm{LH} \\
(\mathrm{IE} / \mathrm{l})\end{array}$ & $\begin{array}{l}\text { Estradiol } \\
(\mathrm{nmol} / \mathrm{l})\end{array}$ & $\begin{array}{l}\mathrm{AMH}^{\mathrm{a}} \\
(\mu \mathrm{g} / \mathrm{l})\end{array}$ \\
\hline 3 days & 30 & 8.8 & 0.05 & - \\
2 weeks & 80 & 33 & 0.07 & - \\
2 months & 57 & 53 & $0.25^{\mathrm{b}}$ & - \\
5 months & $7.5^{\mathrm{b}}$ & $6^{\mathrm{b}}$ & $0.39^{\mathrm{b}}$ & $1.7^{\mathrm{b}}$ \\
\hline
\end{tabular}

${ }^{a} \mathrm{AMH}$ normal range in premenopausal women, $0.3-6.8 \mu \mathrm{g} / 1$

${ }^{\mathrm{b}}$ Normalized values age, conservative surgery with preservation of the ovary should be encouraged. Many of these patients have been managed by salpingo-oophorectomy since it was traditionally believed that a delayed diagnosis of an ovarian torsion leads to the irreversible ischemic damage and necrosis of the ovary. Still there are no established criteria to help us distinguish between the twisted ovaries that are salvageable and the ovaries where the irreversible ischemic damage has already occurred. Oelsner et al. reported a series of 102 cases of twisted ischemic adnexa treated conservatively by detorsion that were successfully preserved [5]. The time from symptom onset to surgery, in this series, ranged from 2 to $144 \mathrm{~h}$, with a median of $16 \mathrm{~h}$. Some authors advocate preservation of the ovary regardless of macroscopic appearance or evidence of reperfusion [6,7]. This is in accordance with our case where successful conservation is achieved approximately $240 \mathrm{~h}$ after symptom onset. Thus, saving the ovary should always be treatment of choice, before oophorectomy or adnexectomy.

Another reason for advocating salpingo-oophorectomy in the past as treatment was that the preservation of the adnexa was considered a risk factor for embolism or infection. The incidence of pulmonary embolism in the case of adnexal torsion is $0.2 \%$ [8] and is, however, not increased after untwisting the adnexa [9].

In the reported patient, who previously had the other ovary removed, we had the possibility to observe the recovery clinically and in terms of hormone measurement. After detorsion, Cil et al. have reported power Doppler signals in the ovary within the first $24 \mathrm{~h}$ and decrease of the ovarian size after the edema had resolved [10]. Our patient had a slower normalizing, probably related to delayed diagnosis, prolonged preoperative symptoms, and the 10$\mathrm{cm}$-large ovary. She also experienced temporary climacteric symptoms with hot flashes. Long duration of torsion and considerable edema are probably important for the recovery time of ovarian function after detorsion.

There has been little focus on the endocrine function after detorsion. In our case report, estradiol was normalized after 2 months, while gonadotropin and AMH levels were normalized within 5 months, indicating normal fertility capacity. In addition to transvaginal ultrasound and power Doppler examinations, we believe hormone analyses give valuable information in the follow-up after detorsion of the final ovary.

\section{Conclusion}

Ovarian endocrine function and follicle growth may return several months after adnexal detorsion, and we emphasize the importance of ovarian salvage trial, even in cases with several days of delay in diagnosis. 
Acknowledgments The hormone analyses were kindly performed by The Hormone Laboratory, Oslo University Hospital Aker, Oslo, Norway.

Declaration of interest The authors report no conflicts of interest. The authors alone are responsible for the content and writing of the paper.

\section{References}

1. Cohen SB, Oelsner G, Seidman DS, Admon D, Mashiach S, Goldenberg M (1999) Laparoscopic detorsion allows sparing of the twisted ischemic adnexa. J Am Assoc Gynecol Laparosc 6:139-143

2. Way S (1946) Ovarian cystectomy of twisted cysts. Lancet 2:4748

3. Oelsner G, Bider D, Goldenberg M, Admon D, Mashiach S (1993) Longterm follow-up of the twisted ischemic adnexa managed by detorsion. Fertil Steril 60:976-979
4. Göcmen A, Karaca M, Sari A (2008) Conservative laparoscopic approach to adnexal torsion. Arch Gynecol Obstet 277:535-538

5. Oelsner G, Cohen SB, Soriano D, Admon D, Mashiach S, Carp H (2003) Minimal surgery for the twisted ischaemic adnexa can preserve ovarian function. Hum Reprod 18(12):2599-2602

6. Bider D, Mashiach S, Dulitzky M, Kokia E, Lipitz S, Ben-Rafael Z (1991) Clinical, surgical and pathologic findings of adnexal torsion in pregnant and nonpregnant women. Surg Gynecol Obstet 173:363

7. Shalev J, Goldenberg M, Oelsner G, Ben-Rafael Z et al (1989) Treatment of twisted ischemic adnexa by simple detorsion. N Engl Med 24:546

8. Oelsner G, Shashar D (2006) Adnexal torsion. Clin Obstet Gynecol 49:459-463

9. McGovern PG, Noah R, Koenigsberg R, Littele AB (1999) Adnexal torsion and pulmonary embolism: case report and review of the literature. Obstet Gynecol Surv 54:601-608

10. Cil AP, Akgul MA, Tulunay G, Atayar YY (2006) Recovery of ovarian function after detorsion: Doppler findings. Acta Radiol 47:618-620 